\title{
CLINICAL, PHYSIOLOGICAL, AND PATHOLOGICAL CONSIDERATIONS IN PATIENTS WITH IDIOPATHIC PULMONARY HYPERTENSION
}

\author{
BY \\ JOHN T. SHEPHERD,* JESSE E. EDWARDS, HOWARD B. BURCHELL, \\ H. J. C. SWAN, AND EARL H. WOOD \\ From the Sections of Physiology, Pathology, and Medicine, Mayo Clinic and Mayo Foundation, $\dagger$ \\ Rochester, Minnesota, U.S.A.
}

Received November 1, 1955

Cases of idiopathic pulmonary hypertension are uncommon. Paul Wood (1950) found 6 examples among 233 unselected patients suspected of having congenital heart disease, 152 of whom were catheterized. Dresdale et al. (1951) encountered four cases and mentioned that ten cases of pulmonary hypertension without demonstrable cause in which cardiac catheterization had been performed had been reported.

To place patients into this group on the basis of clinical and physiological studies requires that all the conditions of which pulmonary hypertension is but one feature be excluded. There must be, for example, evidence of a normal mitral valve, of a competent left ventricle, and of absence of an abnormal communication between the lesser and greater circulations; and primary disease of the pulmonary parenchyma of the types that narrow the pulmonary vascular bed must have been eliminated. However, even after the most careful clinical and physiological studies, unsuspected malformations of which pulmonary hypertension is a functional accompaniment may at times be demonstrated at necropsy in a case that has been designated as an example of idiopathic pulmonary hypertension.

This communication presents the clinical and physiological findings in ten patients with pulmonary hypertension. In these ten none of the disease states known to be associated with raised pulmonary arterial pressure was demonstrated clinically or physiologically. In four a venoarterial (right-to-left) shunt was present at the atrial level. Necropsy was done in three of them, in two of which there had been veno-arterial shunts. One of these (Case 8) in which an atrial septal defect of moderate size was present, should be excluded from this paper on the basis of the definition of the syndrome of idiopathic pulmonary hypertension, but careful consideration of the clinical and physiological data, even after the true nature of the condition was known, revealed no feature that would distinguish it from the others reported: hence for reasons of discussion the data for this case have been fully reported.

\section{SPECIAL INVESTIGATIONS}

Cardiac catheterization was carried out on each patient, using techniques previously described (E. H. Wood, 1950 and 1953). Intravascular pressures were measured by strain-gauge manometer systems (Wood and Sutterer, 1955). The oxygen saturation of blood samples from the heart and great vessels was determined by manometric (Van Slyke and Neill, 1924) and photometric techniques (Wood, 1950).

The objectives at cardiac catheterization are to exclude the presence of any arterio-venous shunt, to exclude a veno-arterial shunt from the right ventricle or pulmonary artery, to obtain the pulmonary arterial and pulmonary arterial "wedge" pressures (Connolly et al., 1954) and to determine the pulmonary and

* Present address: Department of Physiology, The Queen's University, Belfast, Northern Ireland.

† The Mayo Foundation, Rochester, Minnesota, is a part of the Graduate School of the University of Minnesota. 
systemic flows and resistances. We believe that in many instances it may be difficult or impossible to decide on the presence or absence of intracardiac or great vessel shunts solely on the basis of the oxygen saturation values of the blood determined by manometric methods. Hence the particular applications of techniques in current use in our laboratory are outlined briefly below.

Oximetry. The absolute reading cuvette oximeter (Wood, 1950), an instrument of high relative accuracy, permitted an immediate reading to be obtained of the oxygen saturation of the blood in the heart and great vessels. Determinations of the oxygen saturation could be made in rapid succession from various sites and, if the significance of any change in saturation was in question, the series of determinations could be repeated as often as required. Such instrumentation greatly facilitates the identification of small arteriovenous shunts by the demonstration of an abnormal difference in oxygen saturation of blood samples withdrawn from the cavæ, right atrium, right ventricle, or pulmonary artery.

Indicator-dilution Techniques. Dye-dilution curves were also used to exclude the presence of any abnormal communication in the heart or great vessels (Nicholson et al., 1951; Broadbent and Wood, 1954) and to localize such a defect if it existed (Swan and Wood, 1953; Swan et al., 1954). This method is especially valuable for the identification and localization of veno-arterial shunts that cannot be localized and, if small, cannot be identified from the oxygen saturation of the arterial blood. The dye-dilution curves were recorded by means of a cuvette oximeter through which blood from the radial artery was permitted to flow, and simultaneously by means of oximeters attached to the pinna of each ear. In some of the earlier cases injections of dye into a peripheral vein only were carried out, while in the cases studied more recently dye injections were made into the chambers of the heart and great vessels through the cardiac catheter (Swan and Wood, 1953).

Inhalation of Gas Mixtures of Different Oxygen Content. The magnitude of an arterio-venous shunt can often be increased if the patient is given 100 per cent oxygen to breathe, and the magnitude of a veno-arterial shunt can often be increased when low-oxygen mixtures are administered (Burchell et al., 1953).

Radial and Femoral Arterial Blood Samples. The presence of a patent ductus arteriosus with reversal of flow through the ductus can be recognized if the oxygen content of the femoral arterial blood is found to be significantly lower than that of blood withdrawn at the same time from an artery in the right arm (Hultgren et al., 1953; Burchell et al., 1953). If the difference in saturation is of doubtful significance, it can be accentuated if the patient breathes low-oxygen mixtures. Indicator-dilution curves recorded simultaneously at each of these sites will differ from one another if a veno-arterial shunt through a patent ductus arteriosus is present (Burchell et al., 1953).

Simultaneous Recording of Pulmonary and Systemic Arterial Pressures. In patients with equal pressures in the right and left ventricles, a change in the relation of the pulmonary-arterial pressure to the simultan:eously recorded systemic arterial pressure produced by exercise or by breathing a different oxygen mixture tends to exclude the presence of a patent ductus or ventricular septal defect as the cause of the pulmonary hypertension.

Pulmonary Arterial "Wedge" Pressure. The pulmonary arterial "wedge" pressure should always be obtained in order that obstruction to the pulmonary-venous flow as a cause of the hypertension can be excluded. It has been our experience, however, in certain patients with severe pulmonary hypertension that the catheter may not be advanced into the wedged position in spite of persistent efforts.

\section{Presentation of Data}

Clinical Data. The ages of the 10 patients ranged from 24 to 46 years. Nine were women. All complained primarily of increasing weakness and dyspnœa on exertion. The duration of these symptoms varied from a month to 18 years (Table I). Seven of the patients had had one or more attacks of syncope on exertion. An attack, observed in one patient by her home physician, took place when she was carrying out an exercise test: moderate sinus tachycardia was followed by nodal bradycardia when she lost consciousness; there was no convulsion or incontinence. Five of the patients had thoracic pain on effort, which had the general characteristics of angina pectoris: the pain varied from a feeling of pressure in the thorax to pain starting in the chest and extending down both arms. No patient had orthopnœa, paroxysmal dyspnœa, or hæmoptysis, with the exception of one (Case 10), who had had intermittent hæmoptysis for a period of ten days about six weeks before admission.

The characteristic physical finding in all the patients was an accentuated second sound in the 
pulmonary area. Four patients had, in addition, a pulmonary diastolic murmur which may have been due to functional incompetence of the pulmonary valve. At catheterization the pulmonary arterial pulse pressure was not significantly greater in these four than in the others of this series. In one a pulmonary systolic murmur of grade I intensity was present. In another, originally referred for possible mitral valvular disease, there was a systolic murmur of grade I intensity at the apex. When this patient returned five months later she had a left recurrent laryngeal nerve paralysis, the systolic murmur had increased in intensity, and a diastolic third sound with a prominent triple

TABLE I

Principal Features in 10 Patients with the Clinical Diagnosis of IDIOPATHIC PULMONARY HYPERTENSION

\begin{tabular}{|c|c|c|c|c|c|c|c|c|c|}
\hline Case & $\begin{array}{l}\text { Age, } \\
\text { years, } \\
\text { and } \\
\text { sex }\end{array}$ & $\begin{array}{l}\text { Pregnancies } \\
\text { or } \\
\text { miscarriages }\end{array}$ & $\begin{array}{l}\text { Duration } \\
\text { of } \\
\text { symptoms }\end{array}$ & Dyspnœa & $\begin{array}{l}\text { Chest } \\
\text { pain }\end{array}$ & Syncope & $\begin{array}{l}\text { Right } \\
\text { heart } \\
\text { failure }\end{array}$ & $\begin{array}{l}\text { Prominence } \\
\text { of pulmonary } \\
\text { arterial } \\
\text { shadow }\end{array}$ & $\begin{array}{c}\text { E.C. right } \\
\text { ventricular } \\
\text { hypertrophy }\end{array}$ \\
\hline $\begin{array}{l}1 \chi \\
2 \\
3 \\
4 \\
5 \\
6 \\
7 * \\
8^{*} \chi \\
9 * x \\
10^{*}\end{array}$ & $\begin{array}{l}24 \mathrm{~F} \\
32 \mathrm{~F} \\
35 \mathrm{~F} \\
42 \mathrm{~F} \\
43 \mathrm{~F} \\
46 \mathrm{~F} \\
24 \mathrm{~F} \\
27 \mathrm{M} \\
30 \mathrm{~F} \\
38 \mathrm{~F}\end{array}$ & $\begin{array}{l}4 \\
? \\
5 \\
1 \\
3 \\
- \\
- \\
-\end{array}$ & $\begin{array}{rl}1 & \mathrm{mo} . \\
1 \frac{1}{2} & \mathrm{yr} . \\
8 & \mathrm{yr} . \\
11 & \mathrm{yr} . \\
16 & \mathrm{yr} . \\
7 & \mathrm{yr} . \\
7 & \mathrm{yr} . \\
18 & \mathrm{yr} . \\
1 \frac{1}{2} & \mathrm{yr} . \\
5 & \mathrm{yr} .\end{array}$ & $\begin{array}{c}+ \\
+ \\
++ \\
++ \\
++ \\
+ \\
++ \\
++ \\
++ \\
++\end{array}$ & $\begin{array}{c}+ \\
0 \\
0 \\
0-+ \\
+ \\
0 \\
0 \\
+ \\
++ \\
0\end{array}$ & $\begin{array}{c}+ \\
+ \\
+ \\
0 \\
++ \\
++ \\
+ \\
++ \\
0 \\
0\end{array}$ & $\begin{array}{l}0 \\
+ \\
0 \\
+ \\
0 \\
0 \\
0 \\
0 \\
0 \\
+\end{array}$ & $\begin{array}{c}+ \\
++ \\
+ \\
++ \\
++ \\
++ \\
++ \\
++ \\
+ \\
+\end{array}$ & $\begin{array}{l}++ \\
++ \\
++ \\
++ \\
++ \\
++ \\
++ \\
++ \\
++ \\
0-+\end{array}$ \\
\hline
\end{tabular}

* Complicated by an atrial veno-arterial shunt.

$0=$ absent. $\quad+=$ mild to moderate. $\quad++=$ severe. $\chi=$ necropsy performed.

rhythm was present. The findings, however, could not be interpreted as indicating mitral stenosis, and at catheterization the pulmonary arterial wedge pressure was normal, a fact which suggested that no obstruction existed at the mitral valve. A normal mitral valve was later demonstrated at necropsy.

The electrocardiogram showed right ventricular hypertrophy in all cases. The $\mathbf{P}$ waves in six cases had a peaked configuration and exceeded $0.25 \mathrm{mV}$ in one or more leads. X-ray examination showed a prominent pulmonary arterial segment and evidence for right ventricular hypertrophy (Table I). The peripheral pulmonary fields showed normal or diminished vascular shadows and no evidence of parenchymal disease. In no case did physiological studies of pulmonary function (Fowler and Miller, 1954) reveal a respiratory basis for the dyspnœa on exertion. The results of serological tests for syphilis were negative in every case.

The only patients cyanosed at rest were Cases 2,8 , and 10 .

Hamodynamic Data. The data obtained at catheterization are summarized in Table II. The pulmonary arterial pressure was always greatly increased, averaging $111 / 59 \mathrm{~mm}$. The radial arterial pressure averaged $130 / 84 \mathrm{~mm}$. The pulmonary arterial wedge pressure was obtained in six and was within normal limits, and the pressure in the right atrium was raised in six cases. Of the four with a veno-arterial shunt, three had right atrial pressures within the range of normal.

The pulmonary flow was always below the range of normal and averaged $1.61 . / \mathrm{min} . / \mathrm{M}^{2}$. In 12 normal subjects of a similar age group studied in our laboratory, it averaged $3.41 . / \mathrm{min} . / \mathrm{M} .{ }^{2}$. In two of the patients who did not have a shunt the value for pulmonary flow was determined during moderate exercise: in one it did not change and in the other it increased only from 1.2 to 2.0 1./min./M.2.

The total pulmonary resistance in all the patients was very hign, averaging 2690 dynes $/ \mathrm{sec} . / \mathrm{cm}^{-5}$. In eight of the patients the change in total pulmonary resistance when pure oxygen was breathed instead of air was determined (Table III). With one exception (Case 8) there was no significant 
TABLE II

Data Obtained at Cardiac Catheterization

\begin{tabular}{|c|c|c|c|c|c|c|c|c|c|c|c|c|}
\hline \multirow{3}{*}{ Case } & \multirow{3}{*}{$\begin{array}{l}\text { Age, } \\
\text { years }\end{array}$} & \multicolumn{5}{|c|}{ Pressure, mm. of mercury } & \multirow{3}{*}{$\begin{array}{c}\text { Pulmonary } \\
\text { flow } \\
(1 . / \mathrm{min} . / \\
\left.\mathrm{M}^{2} .\right)\end{array}$} & \multirow{3}{*}{$\begin{array}{c}\text { Total } \\
\text { pulmonary } \\
\text { resistance } \\
\text { (dynes sec. } \\
\mathrm{cm} .^{-5} \text { ) }\end{array}$} & \multirow{2}{*}{\multicolumn{2}{|c|}{$\begin{array}{c}\text { Oxygen } \\
\text { saturation } \\
\text { percentage } \\
\text { (Van Slyke) } \\
\text { breathing air }\end{array}$}} & \multirow{3}{*}{$\begin{array}{c}\text { Physically } \\
\text { dissolved } \\
\text { oxygen in } \\
\text { radial } \\
\text { artery } \\
\text { blood* } \\
\text { (volume } \\
\text { per } 100 \mathrm{ml} \text {.) }\end{array}$} & \multirow{3}{*}{$\begin{array}{l}\text { Hæmo- } \\
\text { globin } \\
\text { (g. per } \\
100 \mathrm{ml} . \\
\text { blood) }\end{array}$} \\
\hline & & \multirow{2}{*}{$\begin{array}{c}\text { Radial } \\
\text { artery } \\
\text { S/D }\end{array}$} & \multicolumn{2}{|c|}{$\begin{array}{l}\text { Pulmonary } \\
\text { artery }\end{array}$} & \multirow{2}{*}{$\begin{array}{c}\text { Pulmonary } \\
\text { arterial } \\
\text { wedge" } \\
\text { (mean) }\end{array}$} & \multirow{2}{*}{$\begin{array}{c}\text { Right } \\
\text { atrium }\end{array}$} & & & & & & \\
\hline & & & S/D & Mean & & & & & $\begin{array}{l}\text { Radial } \\
\text { artery }\end{array}$ & $\begin{array}{c}\text { Pul- } \\
\text { monary } \\
\text { artery }\end{array}$ & & \\
\hline $\begin{array}{r}1 \\
2 \\
3 \\
4 \\
5 \\
6 \\
7 \dagger \\
8 \dagger \\
9 \dagger \\
10 \dagger\end{array}$ & $\begin{array}{l}24 \\
32 \\
35 \\
42 \\
43 \\
46 \\
24 \\
27 \\
30 \\
38\end{array}$ & $\begin{array}{l}109 / 76 \\
130 / 86 \\
155 / 110 \\
135 / 75 \\
146 / 94 \\
150 / 80 \\
100 / 76 \\
114 / 66 \\
114 / 78 \\
150 / 100\end{array}$ & \begin{tabular}{|r|}
$82 / 47$ \\
$100 / 50$ \\
$94 / 51$ \\
$137 / 62$ \\
$144 / 72$ \\
$99 / 35$ \\
$135 / 84$ \\
$133 / 87$ \\
$94 / 52$ \\
$87 / 46$
\end{tabular} & $\begin{array}{r}58 \\
64 \\
69 \\
80 \\
97 \\
57 \\
96 \\
105 \\
69 \\
56\end{array}$ & $\begin{array}{r}4 \\
\overline{8} \\
13 \\
8 \\
5 \\
3 \\
-\end{array}$ & $\begin{array}{l}15 / 8 \\
20 / 10 \\
26 / 15 \\
15 / 7 \\
23 / 7 \\
10 / 3 \\
18 / 6 \\
5 / 0 \\
5 / 1 \\
8 / 5\end{array}$ & $\begin{array}{l}1 \cdot 2 \\
2 \cdot 2 \\
1 \cdot 0 \\
2 \cdot 3 \\
1 \cdot 5 \\
2 \cdot 2 \\
0 \cdot 9 \\
1 \cdot 7 \\
2 \cdot 0 \\
1 \cdot 1\end{array}$ & $\begin{array}{l}2270 \\
1600 \\
3680 \\
1830 \\
3230 \\
1080 \\
6390 \\
2800 \\
1500 \\
2490\end{array}$ & $\begin{array}{l}97 \\
98 \\
95 \\
95 \\
95 \\
97 \\
81 \\
81 \\
96 \\
80\end{array}$ & $\begin{array}{l}52 \\
64 \\
44 \\
68 \\
55 \\
71 \\
42 \\
62 \\
68 \\
47\end{array}$ & $\begin{array}{l}1 \cdot 8 \\
1.8 \\
1.8 \\
1.5 \\
1.6 \\
1.5 \\
0 \cdot 2 \\
0 \cdot 1 \\
2.0 \\
0.2\end{array}$ & $\begin{array}{l}13 \cdot 3 \\
15 \cdot 6 \\
17.6 \\
16.0 \\
16.0 \\
14 \cdot 2 \\
18.2 \\
20 \cdot 1 \\
15.3 \\
18.7\end{array}$ \\
\hline
\end{tabular}

* Oxygen content minus oxygen capacity while patients breathed 100 per cent oxygen.

$\dagger$ In these patients an atrial veno-arterial shunt coexisted.

decrease. The polycythæmia which was present in six patients (hæmoglobin values ranging from 16 to $20 \cdot 1 \mathrm{~g}$. per $100 \mathrm{ml}$.) may have contributed slightly to the increase in calculated vascular resistance.

Patients Without a Veno-arterial Shunt. There was no evidence in Cases 1-6, either from the oxygen saturation of the blood in the right heart and pulmonary artery, or from arterial dilution curves of T-1824, of any abnormal communication in the heart or great vessels. The blood from the radial artery was 95-98 per cent saturated with oxygen when these patients were breathing air and fully saturated when breathing pure oxygen, with 1.5-1.8 volumes of oxygen per $100 \mathrm{ml}$. of blood in physical solution. In two of these who were studied during exercise there was no fall in arterial oxygen saturation. The indicator-dilution curves for Case 2, shown in Fig. 1, give evidence of the absence of an intracardiac shunt. In this and the other patients without a shunt (Cases 1,3-6) the only abnormality of the dye curve was the prolongation of the time components associated with a " reduced" cardiac output. In Case 2 there was clinical evidence of tricuspid insufficiency.

TABLE III

Change in Pulmonary Arterial Pressure, Pulmonary Blood Flow and Total Pulmonary Resistance When the Patients Breathed 100 Per Cent Oxygen

\begin{tabular}{|c|c|c|c|c|c|c|c|}
\hline \multirow[t]{2}{*}{ Case } & \multicolumn{2}{|c|}{$\begin{array}{l}\text { Mean pulmonary arterial } \\
\text { pressure }(\mathrm{mm} . \mathrm{Hg})\end{array}$} & \multicolumn{2}{|c|}{$\begin{array}{l}\text { Pulmonary flow } \\
\text { (1./min.) }\end{array}$} & \multicolumn{2}{|c|}{$\begin{array}{l}\text { Total pulmonary } \\
\text { resistance } \\
\text { (dynes sec. } \mathrm{cm} .^{-5} \text { ) }\end{array}$} & \multirow{2}{*}{$\begin{array}{l}\text { Percentage change } \\
\text { in resistance } \\
\text { with oxygen }\end{array}$} \\
\hline & Air & Oxygen & Air & Oxygen & Air & Oxygen & \\
\hline $\begin{array}{c}2 \\
3 \\
4 \\
5 \\
6 \\
7^{*} \\
8^{*} \\
10^{*}\end{array}$ & $\begin{array}{r}64 \\
69 \\
80 \\
97 \\
57 \\
96 \\
105 \\
56\end{array}$ & $\begin{array}{l}67 \\
72 \\
77 \\
91 \\
56 \\
96 \\
97 \\
56\end{array}$ & $\begin{array}{l}3 \cdot 2 \\
1 \cdot 5 \\
3 \cdot 5 \\
2 \cdot 4 \\
4 \cdot 2 \\
1 \cdot 2 \\
3 \cdot 0 \\
1 \cdot 8\end{array}$ & $\begin{array}{l}3 \cdot 1 \\
1 \cdot 2 \\
3 \cdot 3 \\
2 \cdot 3 \\
4 \cdot 7 \\
1 \cdot 3 \\
3 \cdot 5 \\
2 \cdot 1\end{array}$ & $\begin{array}{l}1600 \\
368 J \\
1830 \\
3230 \\
1080 \\
6390 \\
2800 \\
2490\end{array}$ & $\begin{array}{r}1730 \\
4800 \\
1860 \\
3160 \\
950 \\
5900 \\
2220 \\
2130\end{array}$ & $\begin{array}{r}+8 \\
+30 \\
+2 \\
-2 \\
-12 \\
-8 \\
-21 \\
-14\end{array}$ \\
\hline
\end{tabular}

* In these patients an atrial veno-arterial shunt coexisted. 
Patients With a Veno-arterial Shunt. In three of the others (Cases 7, 8, and 10) there was desaturation of arterial blood at rest due to a veno-arterial shunt at atrial level. In Case 8 the arterial oxygen saturation dropped from 86 to 54 per cent with exercise. Case 9, who also had a venoarterial shunt at atrial level, had a normal arterial saturation at rest, but this decreased to 74 per cent with exercise. The noteworthy findings are described separately for each case.

Case 7. There was no evidence of any arterio-venous shunt from the $\mathrm{O}_{2}$ saturation of the blood from the right side of the heart. However, the radial arterial blood was only 84 per cent saturated. Calculations on the basis of oxygen-saturation data indicated that about 25 per cent of the systemic flow was derived from a veno-arterial shunt. The direction and magnitude of the shunt were unchanged when this patient breathed pure oxygen instead of air. The dye-dilution curves (Fig. 2) demonstrated a right-to-left shunt of approximately 25 per cent at the atrial level (Swan et al., 1953).

Case 8. This man, aged 27, was cyanosed at rest. When he was 9 years old his parents were first told that he had heart trouble and cyanosis was present: the time of onset of the cyanosis was uncertain. At catheterization repeated determinations of the oxygen saturation of blood in the I.V.C., R.A., and S.V.C. failed to demonstrate the presence of an arterio-venous shunt. The arterial $\mathrm{O}_{2}$ saturation was only 81 per cent when the patient was breathing air and it was estimated that 40 per cent of the systemic blood came from a veno-arterial shunt. The dye-dilution curves demonstrated a large veno-arterial shunt at the atrial level. 
Because of the progressive nature of this patient's symptoms he elected to undergo surgical closure of the defect, which was successfully accomplished. He appeared to be improved, for his cyanosis had disappeared, but about 72 hours after operation he died suddenly. At necropsy he was found to have an atrial septal defect, measuring $2.5 \mathrm{~cm}$. in diameter, and extensive organic pulmonary vascular changes.

The final diagnosis in this case is atrial septal defect with pulmonary hypertension and not idiopathic pulmonary hypertension, as had been suggested by the physiological and clinical findings.

INJECTION

DYE CONC.

INTO:

mg./L.
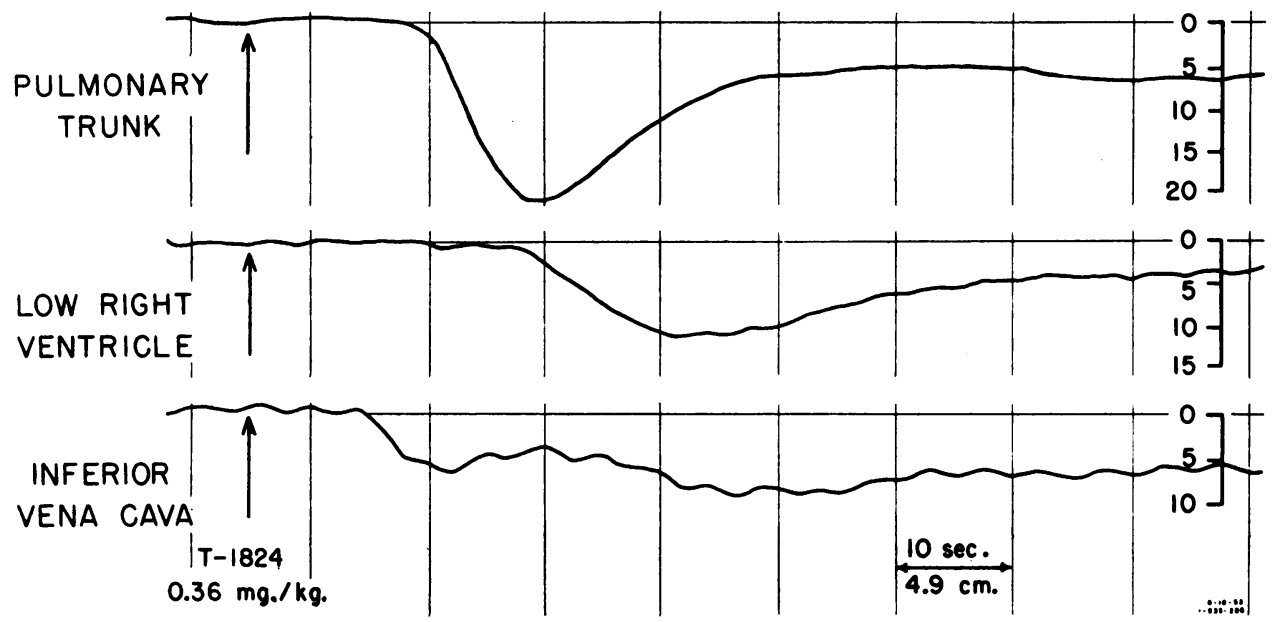

FIG 2.-(Case 7). Arterial indicator-dilution curves recorded by means of an oximeter attached to the ear, following injections of T-1824 into $(a)$ main pulmonary artery, $(b)$ lower part of right ventricle, and $(c)$ inferior vena cava, while the patient breathed 100 per cent oxygen. The curves following dye injections into the pulmonary artery and lower part of the right ventricle are prolonged in their time components but do not indicate any arterio-venous shunt or a veno-arterial shunt at or distal to the lower part of the right ventricle. The curve following injection into the inferior vena cava differs in that the time of first appearance of the dye is shorter and there is an early initial peak of dye concentration. This is due to indicator shunted across an interatrial communication and so reaching the systemic circulation before the remainder of the dye, which has to traverse the pulmonary vascular pathway.

Case 9. The radial arterial blood had a normal complement of oxygen $(96 \%$ saturated) with the patient at rest and breathing air, and when she was breathing pure oxygen, 2 volumes of oxygen per $100 \mathrm{ml}$. were present in physical solution. The dye-dilution curves at rest indicated that a veno-arterial shunt existed at the atrial level which amounted to about 6 per cent of the systemic flow. During exercise, however, even when pure oxygen was breathed, the saturation fell to 86 per cent. There was no evidence of any arterio-venous shunt either from the oxygen-saturation values at cardiac catheterization or from the dye-dilution curves. This patient also elected to have a surgical correction of the interatrial communication, but died during the operation. A valve-competent type of patent foramen ovale was demonstrated at necropsy, as the only site for a shunt in the central circulation.

Case 10. The $\mathrm{O}_{2}$ saturation of the arterial blood was 80 per cent at rest. There was no evidence of an arterio-venous shunt. From the saturation data it was calculated that about 40 per cent and 29 per cent of the systemic flow was composed of shunted blood when the patient breathed air and oxygen respectively. The dye-dilution curves were interpreted to indicate the presence of a moderate right-to-left shunt occurring at atrial level and an insufficiency of the tricuspid valve of significant degree.

\section{Pathological Examination in Cases 1, 8, and 9}

Case 1. We are indebted to Drs. L. E. Wold and J. D. LeMar for submitting sections of lung (Fig. 3a).

Histological examination of the lungs revealed that, while many of the arterioles and muscular arteries were normal, some, but particularly the arteries, were affected by occlusive lesions. In the arterioles and the small muscular arteries which were affected, the occlusive lesions consisted of fibrous intimal thickening, at 


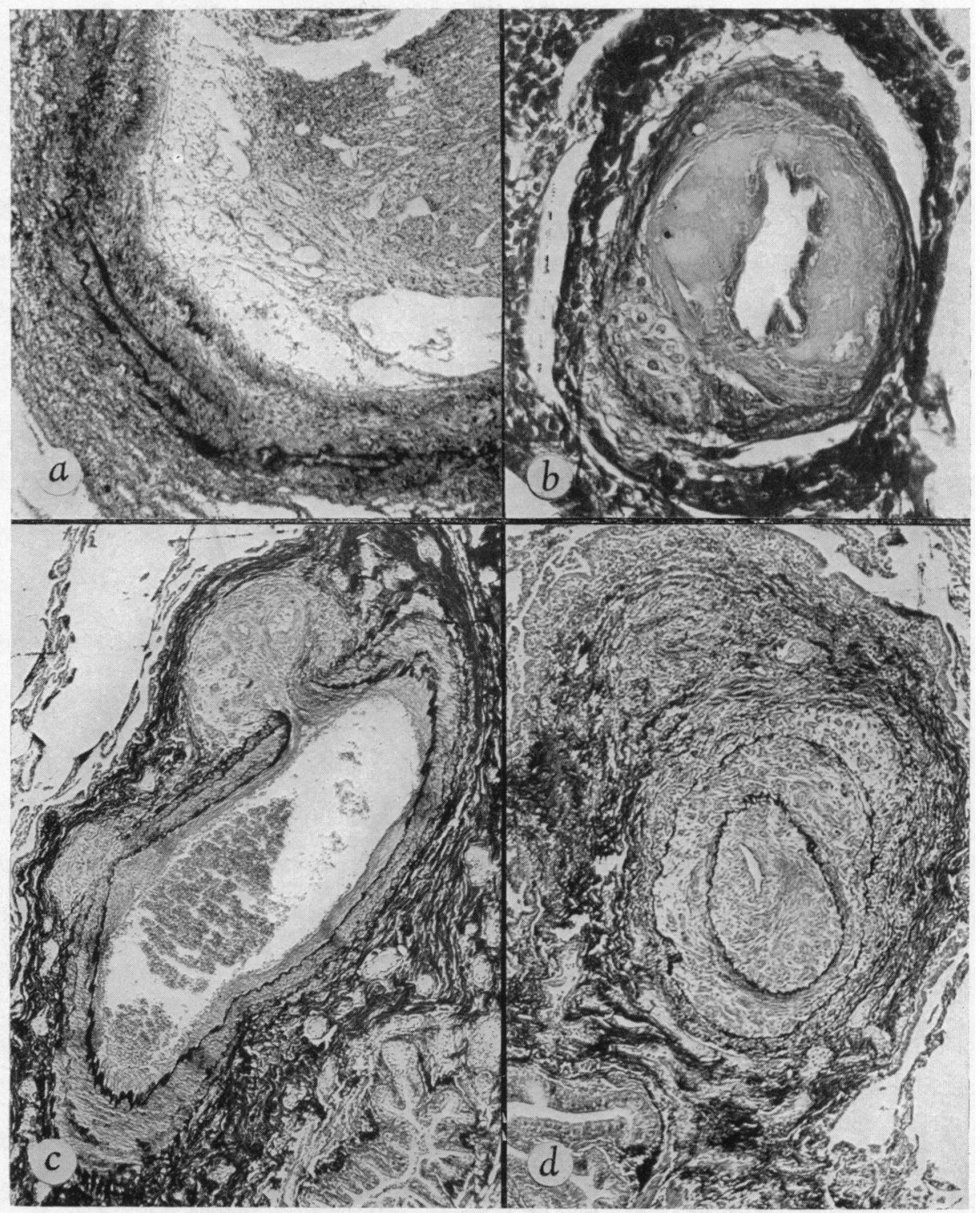

FIG. 3.-Intrapulmonary arteries. (a) (Case 1). Elastic artery, showing a thrombus undergoing organization (EL-VG*; $\times 75)$. (b) (Case 8). Small muscular artery with marked hyaline thickening of the wall associated with luminal narrowing (EL-VG; $\times 250)$. (c) (Case 8). Large muscular artery, showing healed arteritis characterized by focal scarring of the media and localized intimal thickening. Also a branch of this artery is replaced by vascular connective tissue. This formation is interpreted as representing the end stage of a necrotizing process in the arterial branch $(E L-V G ; \times 45)$. (d) (Case 8). Muscular artery of which the lumen is occluded by vascular connective tissue, interpreted as an organized thrombus. The medial and adventitial layers of the vessel are replaced by vascular connective tissue, interpreted as the healed stage of necrotizing arteritis (EL-VG; $\times 50$ ).

* EL-VG=Verhoeff's elastic-tissue stain counterstained with Van Gieson's connective tissue stain. 
times vascularized. The lumina of many of the large muscular arteries and small elastic arteries were found to be filled with thrombotic material in varying stages of active organization.

Medial hypertrophy of muscular arteries was not a striking feature in this case: in many sites none was present, but in some of the large muscular arteries moderate degrees were evident. The alveolar structure of the lung was normal apart from a solitary focus in which there was pneumonia with abscess formation.

Case 8. The pathological examination of the heart revealed an atrial septal defect, measuring $2.5 \mathrm{~cm}$. in diameter, in the region of the foramen ovale. The heart was enlarged, particularly owing to the thickness of the right ventricle, which on cross-section of the wall measured $1.7 \mathrm{~cm}$., while that of the left ventricle was normal and measured $1.4 \mathrm{~cm}$. The pulmonary trunk was wide, its diameter being $4 \mathrm{~cm}$., while the diameter of the ascending aorta was $2 \cdot 5 \mathrm{~cm}$.

Microscopically, abnormalities in the intrapulmonary vessels were characterized uniformly by pronounced medial hypertrophy of the muscular arteries, particularly of the larger ones. Although in most of the muscular arteries there was little or no intimal fibrous thickening, there were a few in which the lumen was entirely obliterated by fibrous tissue, at times hyalinized (Fig. $3 b$ ): this, when present, was more prominent in the small than in the larger muscular arteries. Occasionally, the latter showed formations in which vascular connective tissue replaced all or portions of the arterial wall (Fig. 3c). At times this was associated with an organized thrombus within the lumen of a recognizable artery (Fig. $3 d$ ). The arterioles did not show lesions.

Case 9. At necropsy the heart weighed $550 \mathrm{~g}$. The ductus arteriosus was closed, and there was no ventricular septal defect. In the atrial septum there was a patent foramen ovale $1.5 \mathrm{~cm}$. in diameter guarded by a competent valve which appeared capable of preventing left-to-right flow, but would allow a right-toleft shunt at atrial level. There was striking concentric right ventricular hypertrophy. The gross appearance of the pulmonary tissue was not remarkable.

Histological examination of the lungs revealed that in many of the arterioles there were severe occlusive lesions characterized by cellular, concentric, fibrous, non-vascular, intimal thickening. In serial sections these lesions were shown to be focal, so that on one level the vessel might appear normal and at another completely occluded (Fig. $4 \mathrm{a}$ and b).

Uniformly there was pronounced medial hypertrophy of the muscular arteries. Serial sections revealed that frequently the lumen of a small muscular artery was much narrower at its origin than in its more peripheral path: less commonly the diameter was essentially the same at the point of origin as beyond (Fig. $4 c$ and $d$ ).

Thrombotic lesions, either recent and undergoing organization, or healed and represented by plexiform vascular connective tissue, were present in an irregular distribution, involving mainly small muscular arteries. By serial sections it could be demonstrated that at a given level an artery could contain an organizing thrombus but show no evidence of inflammation or destruction in its wall: at another level, however, it would show focal fibrinoid necrosis of the vessel wall with cellular infiltration (Fig. $4 e$ and $f$ ). In one artery this was associated with pronounced arterial and periarterial cellular infiltration associated with fibrous narrowing of the lumen. In this instance the infiltrating cells were mainly neutrophils, but in one focus in a periarterial location, multinucleated giant cells formed part of the cellular infiltrate.

\section{COMMENT}

The characteristic clinical features of idiopathic pulmonary hypertension have been described by Dresdale et al. (1951), (1954), P. Wood (1952), and others. Our patients conform to this pattern, and it appears that the syndrome can be explained on the basis of pulmonary hypertension associated with a low and probably fixed cardiac output. Certain features merit more detailed consideration.

Sex Incidence and Pregnancy. With the exception of Case 8, in which an atrial septal defect was found at necropsy, all the patients in this series were female. This introduces the question whether idiopathic pulmonary hypertension may be initiated by non-fatal amniotic embolism. A review of the marital histories of the women revealed that four gave no history of pregnancy. The histological examination of the lungs of the two female cases examined at necropsy (one of whom had been pregnant) showed no features that could be interpreted as residue of amniotic embolism. Though no association with pregnancy can be established, the question remains whether in some way the pulmonary obstructive lesions are related to menstruation, whether the conditions set up by the menstrual cycle can stimulate thrombosis in the pulmonary vessels or in the uterine vessels which in turn leads to small and recurring pulmonary emboli. The arteriolar lesions in Case 9, however uniform, may conceivably be related to previously recurring thrombi or emboli, as postulated for cases of this kind by Barnard (1954). The answer cannot be given at present.

Cyanosis. Peripheral cyanosis may occur even when the arterial oxygen saturation is normal, because high extraction of oxygen consequent to the reduced cardiac output leads to a high degree 


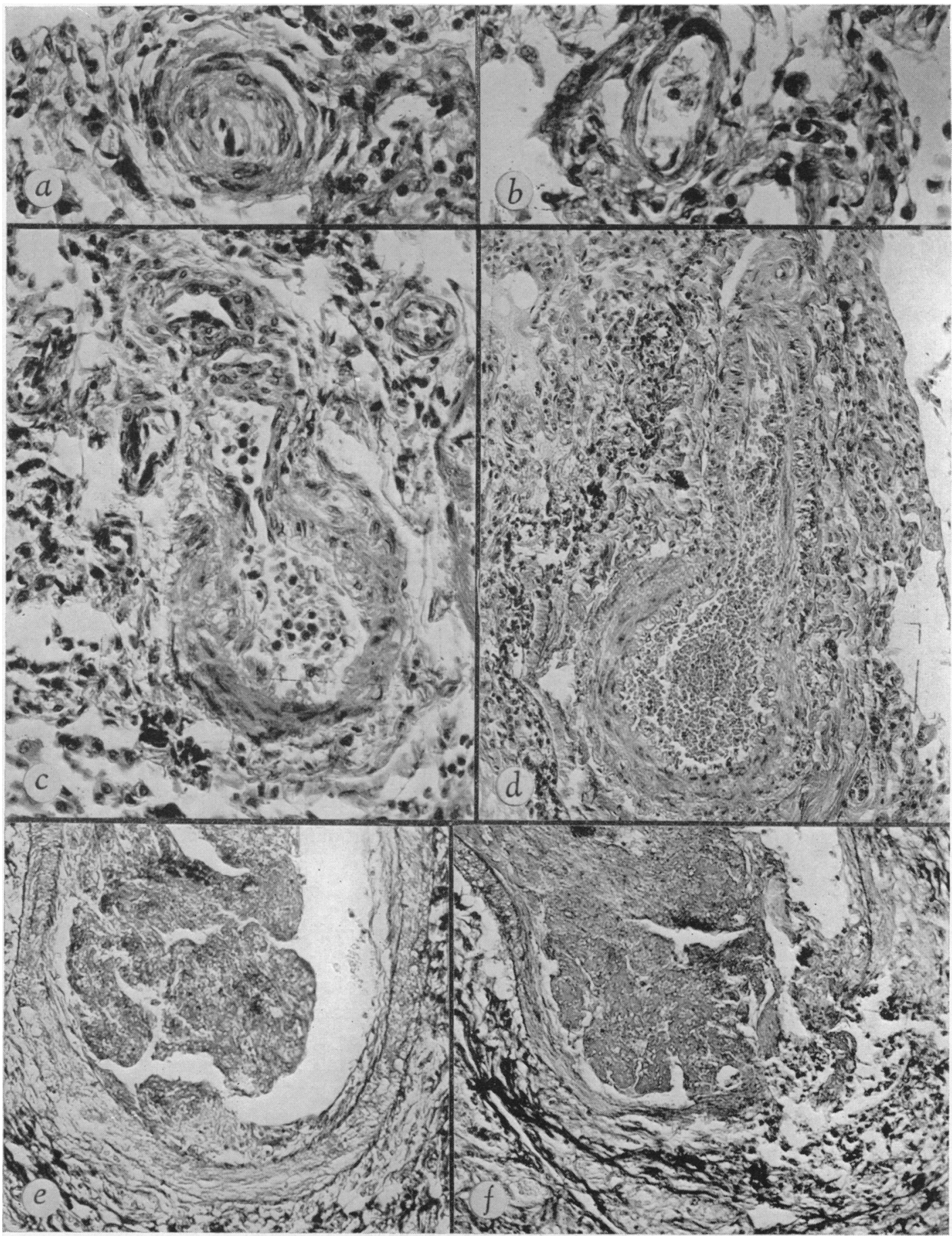

Fig. 4.-(Case 9). Intrapulmonary vessels. (a) Arteriole, showing marked concentric, nonvascular intimal thickening causing virtual obliteration of the lumen (hæmatoxylin and eosin; $\times 310) .(b)$ Same arteriole as illustrated in (a) but at a different level, showing the wall here to be normal (hæmatoxylin and eosin; $\times 310$ ). (c) Large muscular artery and its branch. There is medial hypertrophy, particularly of the parent vessel, and localized narrowing of the branch at its origin. This narrowing was true, as demonstrated by examination of the serial sections (hæmatoxylin and eosin; $\times 250$ ). (d) Muscular artery and its branch, showing no narrowing at the origin of the branch, in contrast to the picture in $(c)$ (hæmatoxylin and eosin; $\times 135)$. (e) Muscular artery containing a thrombus. At this level no significant alterations in the arterial wall existed $(\mathrm{EL}-\mathrm{VG} ; \times 150)$. $(f)$ Same artery as illustrated in $(e)$ but at a different level, showing the thrombus associated with focal fibrinoid necrosis of the arterial wall $(\mathrm{EL}-\mathrm{VG} ; \times 150)$. 
of oxygen unsaturation of the venocapillary blood, as in Case 2; it is not due to arterial hypoxæmia. It is noticeable where the local blood flow is small in relation to the oxygen utilization of the tissues. Desaturation of the arterial blood, when present, is not a consequence of the pulmonary hypertension per se, but results from a veno-arterial shunt through a valve-competent foramen ovale (Cases 7 , 8 , and 10).

Syncope. Seven of the 10 patients gave a history of syncopal attacks. Howarth and Lowe (1953) measured the brachial arterial pressure in two patients with primary pulmonary hypertension and two with the tetralogy of Fallot during induced syncope after exertion. The blood pressure fell gradually after exertion. Sinus bradycardia and loss of consciousness occurred only when the systemic pressure reached low levels. In one patient with pulmonary hypertension, as the systemic pressure fell, the pulse pressure in the right ventricle decreased, with a rise in the diastolic or " filling " pressure. These results indicated an acute failure of the right ventricle due to increase in right ventricular pressure with exercise.

Pulmonary Arterial Wedge Pressure. In the six patients in whom these pressures were obtained, they were within normal limits. In spite of repeated attempts in the others, a wedge pressure was not obtained: there was, however, complete absence of any evidence suggesting disease of the mitral valve or left ventricular failure. Occasionally, when apical murmurs are absent, a case of mitral stenosis may be misinterpreted as an example of idiopathic pulmonary hypertension. In the presence of a diastolic murmur due to functional incompetence of the pulmonary valve following idiopathic pulmonary hypertension, mitral stenosis may be suspected clinically, as in Case 1 of this series. The demonstration of a normal wedge pressure minimizes these two errors.

Pulmonary Resistance. In the presence of a normal wedge pressure and a high total pulmonary resistance, the obstruction to flow is situated proximal to the pulmonary capillary bed. This is the case in idiopathic pulmonary hypertension. Although the average total pulmonary resistance was higher in our 10 cases than in most cases of ventricular septal defect, patent ductus arteriosus, or atrial septal defect and pulmonary hypertension, the resistance may be just as high in individual patients suffering from the latter conditions (Swan et al., 1954). Hence the magnitude of the pulmonary arterial resistance is not in itself of differential value in distinguishing between these conditions.

The inhalation of 100 per cent oxygen frequently decreases the total pulmonary vascular resistance in patients with congenital heart disease and pulmonary hypertension. For example, in six patients not part of this study (four with patent ductus arteriosus and two with ventricular septal defects) in whom the total pulmonary vascular resistance while breathing air varied from 480 to 3215 dynes sec. $\mathrm{cm} .{ }^{-5}$, the decrease varied from 27 to 64 per cent, with an average decrease of 38 per cent. Of the eight cases in the present series in which the effect of breathing oxygen was studied, four showed no change or a slight increase and four showed some decrease, but in only one was this thought to be significant (Table III). While the mechanism by which the oxygen produces a decrease in resistance is unknown, a failure of the resistance to decrease indicates that the calibre of the vessels in the lung remains unchanged, possibly because of the organic changes.

\section{The Presence and Significance of an Intracardiac Shunt}

Special laboratory investigations, including cardiac catheterization, are mandatory if a firm diagnosis of idiopathic pulmonary hypertension is to be made during the life of the patient. The nature of the diagnostic problem differs according to whether or not desaturation of the systemic arterial blood is present. In this regard the variability obtained for normal persons (range of calculated values, 94-5-101 per cent; Wood, 1949) makes it difficult to assess the significance of oxygen saturation values in the lower range of normal. When the arterial saturation exceeds 96 per cent while the patient breathes air, both at rest and during exercise, it is reasonable to assume that there is no impairment of oxygenation in the lungs and that no veno-arterial shunt of significance exists. For patients with systemic arterial saturations which lie in the lower range of normal, additional studies are required to exclude the presence of a veno-arterial shunt.

Patients With Normal Arterial Oxygen Saturation. Of the 10 patients of the present series considered to have idiopathic pulmonary hypertension, six did not have a veno-arterial shunt. One (Case 2) of these 
six was cyanotic, but no arterial desaturation was demonstrated: the cyanosis was considered to be due to a high degree of extraction of oxygen from the capillary blood. In these patients without a veno-arterial shunt the investigations were directed toward excluding arterio-venous shunt at the pulmonary, ventricular, or atrial levels.

Patients With Arterial Desaturation. In patients with arterial desaturation or in patients in whom the systemic arterial saturation is within the range of normal at rest although a veno-arterial shunt of small magnitude is present, a diagnosis of idiopathic pulmonary hypertension can be made only if the venoarterial shunt occurs at the atrial level via a valve-competent foramen ovale. Patent ductus arteriosus, aortico-pulmonary septal defect, and ventricular septal defect complicated by pulmonary hypertension must each be excluded. As mentioned earlier, the use of indicator-dilution techniques makes it possible to solve this problem by establishing the location of a defect through which a veno-arterial shunt is occurring. We have encountered cases of pulmonary hypertension in which studies of the oxygen saturation of the blood gave no significant evidence of any intracardiac shunt, only to find that the technique of selective injection of dye demonstrated the presence of a ventricular septal defect. Hence these cases could be excluded.

The value of the dye-dilution method in localizing the shunt to the artrial level is illustrated by Cases $7,8,9$, and 10 of the present series (Fig. 2). Of the four patients with a veno-arterial shunt at the atrial level only two were definitely cyanosed at rest, although desaturation of the arterial blood at rest was found in three of these four: the fourth (Case 9) had arterial desaturation only on exercise.

In these patients with interatrial communication, the pulmonary hypertension may be idiopathic associated with the secondary opening of a normal valve-competent foramen ovale, or it may represent a complication or a functional accompaniment of a true anatomical atrial septal defect. The presence of a valve-competent (normal) foramen ovale can be excluded if the oxygen saturation of the blood in the right atrium exceeds that in the venæ cavæ. Further, the arterial dilution curves recorded following injection of T-1824 into right and left pulmonary arteries frequently serve to indicate the presence of an atrial septal defect. However, in the presence of negative findings, this differentiation cannot be made. In Case 8 there was no evidence of an arterio-venous shunt, either by repeated oxygen-saturation determinations or by the dye-dilution method. Necropsy subsequently revealed an atrial-septal defect of typical appearance, which measured $2.5 \mathrm{~cm}$. in diameter: the right ventricular wall showed pronounced concentric hypertrophy, but the chamber was not dilated: these features were different from those in patients with atrial septal defect and left-to-right shunts but no pulmonary hypertension, and suggested that a prominent left-ro-right shunt had never been present. The clinical and physiological findings in this patient were entirely consistent with the diagnosis of idiopathic pulmonary hypertension with a right-to-left shunt through a valve-competent foramen ovale. The finding at necropsy of a true anatomical atrial septal defect makes it necessary to reclassify this case as one of atrial septal defect associated with pulmonary hypertension.

In Case 9 the differentiation from atrial septal defect was made when a valve-competent foramen ovale was found at necropsy. In Cases 7 and 10 no final answer can be given as to whether they are examples of idiopathic pulmonary hypertension with patent foramen ovale on the one hand or of atrial septal defect associated with pulmonary hypertension on the other.

\section{Structural Pulmonary Vascular Changes}

The pathological studies made in Cases 1,8 , and 9 do not permit a firm conclusion to be drawn as to the cause of the pulmonary vascular changes. In Case 1 the lesions are consistent with pulmonary embolism or thrombosis, although no recognized cause for either existed. In Case 8 the striking feature was the medial hypertrophy of the muscular arteries, which may represent a persistence of the fotal characteristics of the pulmonary arteries (Civin and Edwards, 1950). In Case 9 the lesions may have been thrombo-embolic in origin, but this cannot be stated with finality.

One feature was brought out by this study: an arteriole that seems normal may in fact at another level be involved by a lesion that entirely occludes its lumen. This may explain some of the opinions expressed in the past which have indicated that the number of occluded arterioles seemed inadequate to be responsible for the degree of elevation of pulmonary pressure present in given cases.

Another feature brought out by the study of serial sections was that at a certain level an artery might be occluded by a bland thrombus which was not associated with changes in the arterial wall. These features would make it difficult to explain the thrombus as having arisen locally and embolism might be given as a probable cause for the occluding thrombus. With serial sections it was shown that 
at other levels the artery occluded by a thrombus might have a necrotizing process in it at which site primary thrombosis occurred: the thrombus seen at another level in the same vessel would then properly be viewed as having been propagated from this primary site.

The presence of necrotizing arterial lesions associated with thrombosis in Case 9 has some bearing on the understanding of lesions in Case 8, where there were foci in arterial walls without the usual elements of the arterial wall. At such sites there was vascular connective tissue. Such lesions, in Case 8, we thought to represent end stages of more acute and necrotizing lesions of the types observed in Case 9. The necrotizing arteritis is considered to be secondary to the presence of the pulmonary hypertension. We have observed this type of lesion both in acute and in healed stages in the lungs of patients with other conditions, all of whom had associated severe pulmonary hypertension, and we believe the arteritis to be a complication of this. The occurrence of such lesions makes one recall that in the systemic circulation necrotizing arteritis may complicate severe hypertension. Thrombotic lesions, both acute and organized, which complicate necrosis of arteries lead to occlusion of vessels. In this way the necrotizing process may be considered to contribute to the pulmonary hypertension. It should not, in our view, be considered an important element in the pathogenesis of pulmonary hypertension, however, since such lesions are comparatively few and they seem to complicate the state in which severe pulmonary hypertension exists rather than to play a role in its inception.

\section{SUMMARY}

This report concerns 10 patients in whom a diagnosis of idiopathic pulmonary hypertension was made on the basis of clinical and physiological studies. Such a diagnosis is chiefly a process of elimination of other types of heart disease of which pulmonary hypertension is a functional accompaniment. The certain differentiation can be made from the great majority of such conditions by the critical application of certain physiological techniques, notably the indicator-dilution method. The only intracardiac shunt consistent with a diagnosis of idiopathic pulmonary hypertension is a veno-arterial shunt through a valve-competent patent foramen ovale. By definition, pulmonary hypertension associated with a true atrial septal defect is not of the idiopathic type. However, the certain differentiation by clinical or physiological methods of a veno-arterial shunt occurring via an unsealed valve-competent foramen ovale or via a true atrial septal defect may be impossible, as attested by Case 8 of the present series.

Post-mortem studies were carried out on the three patients who died. In one, the only man in the series, a true atrial septal defect was found, but the appearance of the heart did not suggest that a large left-to-right shunt had ever been present. The histological appearance of the small pulmonary arteries was varied, but examination of serial sections along the course of a vessel often revealed localized obstructions, which were frequently seen in vessels, the lumina of which were unobstructed throughout most of their length. In the patients studied post mortem the organic changes in the pulmonary vessels appeared sufficient to account for the pulmonary hypertension.

Barnard, P. J. (1954). Brit. Heart J., 16, 93.

\section{REFERENCES}

Broadbent, J. C., and Wood, E. H. (1954). Circulation, 9, 890.

Burchell, H. B., Swan, H. J. C., and Wood, E. H. (1953). Circulation, 8, 681.

Civin, W. H., and Edwards, J. E. (1950). Circulation, 2, 545.

Connolly, D. C., Kirklin, J. W., and Wood, E. H. (1954). Circulation Res., 2, 434.

Dresdale, D. T., Michtom, R. J., and Schultz, M. (1954). Bull. New York Acad. Med., $30,195$.

, Schultz, M., and Michtom, R. J. (1951). Amer. J. Med., 11, 686.

Fowler, W. S., and Miller, R. D. (1954). M. Clin. North America, July, 1227.

Howarth, S., and Lowe, J. B. (1953). Brit. Heart J., 15, 47.

Hultgren, H., Selzer, A., Purdy, A., Holman, E., and Gerbode, F. (1953). Circulation, 8, 15.

Nicholson, J. W., Burchell, H. B., and Wood, E. H. (1951). J. Lab. Clin. Med., 37, 353.

Swan, H. J. C., Burchell, H. B., and Wood, E. H. (1954). Circulation, 10, 705.

-, and Wood, E. H. (1953). Proc. Staff Meet., Mayo Clin., 28, 95.

- , Hetzel, P. S., Burchell, H. B., and Wood, E. H. (1956). Unpublished data.

_-, Zapata-Diaz, J., Burchell, H. B., and Wood, E. H. (1954). Amer. J. Med., $16,12$.

,- J., and Wood, E. H. (1953). Circulation, 8, 70.

G 
Van Slyke, D. D., and Neill, J. M. (1924). J. Biol. Chem., 61, 523.

Wood, E. H. (1948-1949). J. Appl. Physiol., 1, 567.

, In Glasser, O. (1950). Medical Physics. The Year Book Publishers, Inc., Chicago, vol. 2, p. 664.

, (1950). Proc. Staff Meet., Mayo Clin., 25, 384.

(1953). Proc. Staff Meet., Mayo Clin., 28, 58.

(1950). Science, 112, 707.

, and Sutterer, W. (1955). J. Lab. Clin. Med., 45, 153.

Wood. P. (1952). Brit. med. Bull., 8, 348.

-, (1950). Brit. med. J., 2, 639. 